\title{
Cloud Platform Architecture Design of Multiple Participation for Project Cost Based on BIM
}

\author{
Zhenhua Wang ${ }^{1,2}$ and Jun Fang ${ }^{1}$ \\ ${ }^{1}$ School of Civil Engineering and Architecture, Wu Han University of Technology, Wuhan, HB 430070, China; \\ ${ }^{2}$ Faculty of Architectural Engineering, East China University of Technology, Nanchang, JX 330033, China.
}

\begin{abstract}
With the development of information society, the information development of project cost will become an inevitable trend. At present, the management of information project cost in China is still immature. In this paper, using the advantages of BIM project information, considering the work content of different participants in the project cost, a multi-participation cloud platform that meets different functional requirements for project cost will be constructed. The basic ideas and methods of the cloud platform architecture have been proposed from different usage requirements, which lay a solid foundation for promoting the efficiency of project cost management.
\end{abstract}

Keywords - multi-party participation; BIM; project cost; cloud platform

\section{INTRODUCTION}

The development of information technology has made BIM begin to appear in the engineering field, which has opened up new ideas for engineering cost management. On the one hand, the traditional engineering cost management practitioners rely on manual calculation that has low working efficiency and low utilization degree of data, as well as the complexity of project management issues increases the difficulty of the work; on the other hand, the project cost management is an engineering construction economic management, which involved a wide range of management participants and there are many management participants. Therefore, there is a large demand for information in the work and it is easy to change these problems. All these problems in the use of BIM technology structure of participating the project cost based on the cloud platform can be solved easily.

\section{THE SUMMARY OF BIM}

\section{A. The Connotation of BIM}

The concept of Building Information Modeling was initially proposed by Dr. Chuck Eastman of the United States in 1975 . He was thus determined by BIM. "BIM is a digital information model that includes construction projects. All physical characteristics and component information throughout the entire life cycle, including construction progress, process control, and other information." That is to say, based on establishing a unified data standards, BIM brings the project participants, project construction phase and technology concerned and software together, forming a huge engineering information platform for the rapid sharing and transmission[2].

BIM expresses the physical and functional attributes of the project in a digital format, providing the correct basis for the project's life cycle management. On the information resource platform of BIM, each project participant can edit, acquire, update and transmit data according to their own needs. BIM can store all kinds of visual technical achievements such as CAD and BLM in data center, which can be unified with its attributes for all cost participants to use[3]. It is very convenient to solve all kinds of problems in the current cost management.

\section{B. The Suitability of BIM in the Cost Cloud Platform}

\section{1) The dynasty of BIM data}

BIM integrates the parameterized information of the three-dimensional model to form a data center. The information in the database can be input and updated at all time. The participants of cost management can quickly find the specified data through BIM[4]. Therefore, BIM can make data dynamic, and greatly improve the efficiency and accuracy of cost data, increasing the cost management level.

\section{2) The sharing of data}

In traditional cost management, historical data is often lacking as a reference. Historical data often have very large value for project investment estimates. BIM can stored completed project information in the data center to meet the information demand of users [5]. At the same time, information input by different project participants can also be shared with other participants, facilitating the transmission of cost information.

\section{3) Accuracy of calculation}

On the basis of BIM, the cost personnel input the calculation rules of engineering cost calculation, and the system can complete the calculation automatically and quickly, and output the calculation results. It makes the cost personnel's workload decrease greatly, enhances the work efficiency, and can improve the accuracy of the calculation result, facilitating the project cost management refinement.

\section{Status ANALYSIS}

In the 1990s, China's computer technology began to enter the field of engineering construction, which led to the pace of information management of construction cost management. The emergence of some cost software assisted in cost management. Using information technology to promote the 
project cost management in our country has made great progress, but compared to developed countries we are still limited to the relatively narrow range and do not have integrity and consistency, the lack of connection between different tools, and are therefore difficult to achieve transformation and transfer [6]. In addition, some professional network portal features are limited to the distribution and sharing of information, and lack of application analysis of information to provide a higher level of cost management services.

\section{DESIGN GOALS AND PRINCIPLES}

\section{A. Architectural Goals}

The architectural design of cloud cost platform should give full play to the high efficiency, sharing and extensibility of cloud computing, and through BIM's advantages to realize the information sharing of all departments of the project. Combined the actual project cost management, guiding the implementation and service of the project cost cloud platform construction, ensuring the practicality of platform design and clearing the overall framework and function of application based on BIM cloud platform architecture, to meet the requirements of different project participants, introducing the informatization construction cost cloud platform to the public and enhancing the popularity of using [7]. The ultimate goal of the platform design is to reduce the "Three excesses" problem in the traditional engineering cost management, namely to reduce the construction cost of the project and improve the efficiency of investment.

\section{B. Architecture Principles}

\section{1) Availability}

The availability of cloud cost platform architecture is directly related to the functional application of the platform, which is the execution level of the user operation command and the length of operation time. Based on the complexity of the project cost cloud platform of BIM, the response time of system operation needs to be controlled within a reasonable scope, which meets the operational requirements of the cost management personnel.

\section{2) Security}

The problems of cost of cloud platform security including user identity security, when users log in cloud cost platform, the legitimacy of the system needs to authenticated by users, to provide application services, and the implementation of the invasion of illegal users can damage the legitimate business; on the business sharing security issues, one is to ensure the isolation of command operations between different users, the other is hardware security; The data security problem, mainly refers to that the data of the platform center is lost, leakage, maliciously tampering, etc, so it is necessary to pay attention to the backup and encryption of the data.

\section{3) Efficiency}

The efficiency of cloud cost platform work related to the speed of occupation and operation of the space in program design. It is directly related to the user's experience, determining the time and efficiency in cost management work of the platform. The efficiency of physical data center platform design is the most basic hardware conditions. In the architecture design, the procedure and logic should be simplified as much as possible, and the information applications are categorized and processed to optimize the overall operating efficiency of the system.

\section{4) Compatibility}

It is the basic premise of the platform use that the architecture design of the cloud cost platform should be compatible, which mainly refers to the degree of work coordination between the hardware and the software used in the computer physical parts. Platform compatibility relates to the operation of system application functions, the sharing between different software and platforms and the platform and the degree of stability of relevant software operations.

\section{DEMAND ANALYSIS}

\section{A. Using Demand}

All the participants in the construction project have different tasks in the project cost management, so the functional requirements of the platform are different. The design department realizes the optimal plan during the design process; the supervision department shall monitor the project cost within the limit; the construction department control the realization of cost management optimization; cost consulting department is the professional personnel of cost management, providing professional cost management direction; and the cost management department macro-controls the cost management.

\section{B. Hardware Requirements}

Cloud development platform development requires relatively high computer configuration. The development environment includes high-frequency CPU, large capacity memory and cache, gigabit network port, built-in USB interface, the interface software, high-speed broadband, web server, $\mathrm{C}$ language programming, database environment, etc.

\section{Management Requirements}

The management requirements include the node management of the interface for executing the command correctly, the management functions of the platform function rights management, different role user management, and platform operation log management corresponding to the participants' role functions.

\section{Security Requirements}

Security requirements mainly include account security of user name $\log$ in, data storage and backup, problem of the platform operation, fault detection and alarm, operation command execution, etc.

\section{FUnCTIONAL STRUCTURE}

Parties involved in the project cost based on BIM cloud platform according to different needs of each participant will always platform is divided into several architectural function. These are supervision organization sub-platform, design organization sub-platform, cost organization sub-platform, 
construction and construction organization sub-platform, sub-platforms of cost management departments, etc. [8].

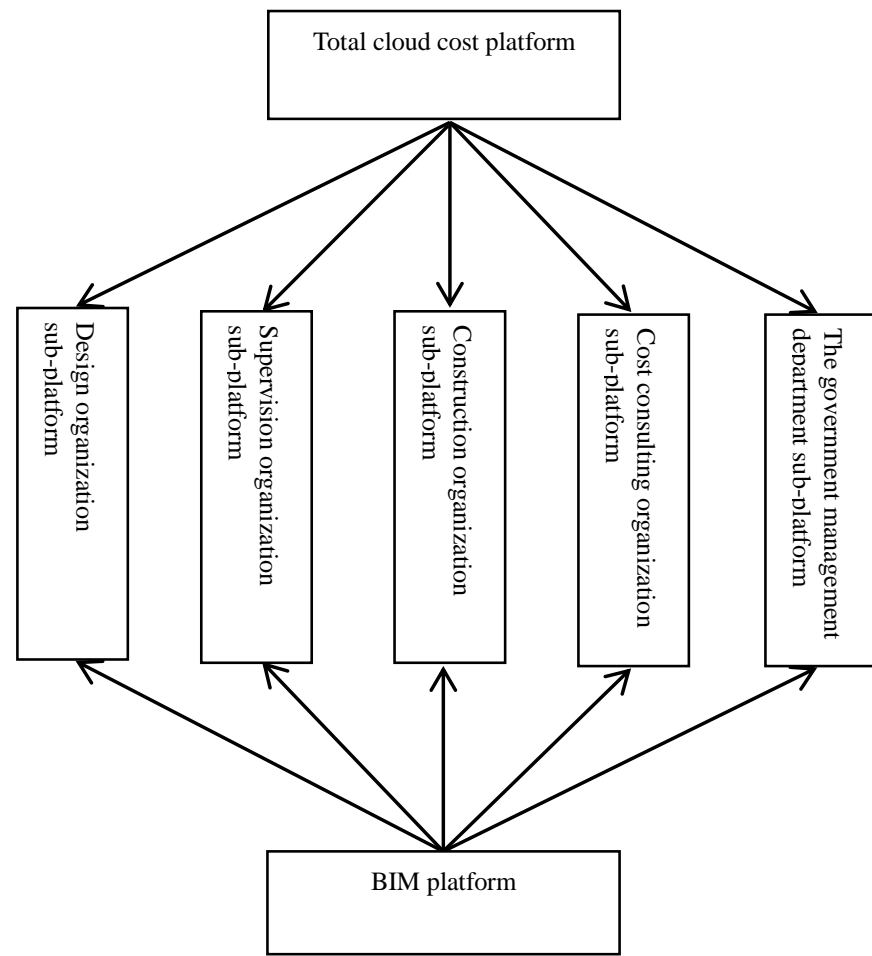

FIGURE I. SCHEMATIC DIAGRAM OF MULTI-PARTY PARTICIPATION IN CLOUD PLATFORM FUNCTION BASED ON BIM PROJECT COST

\section{A. Design Organization Sub-platform}

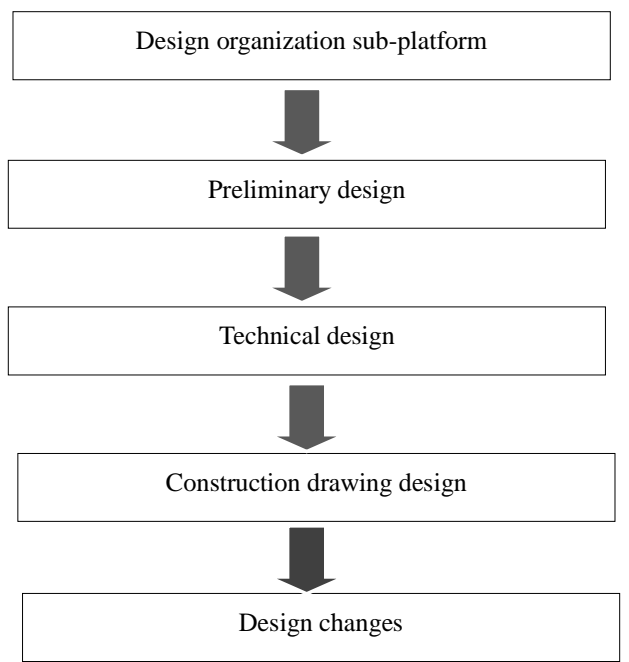

FIGURE II. SCHEMATIC DIAGRAM OF THE FUNCTION OF DESIGN ORGANIZATION SUB-PLATFORM

There are studies show that engineering design of the project cost control the influence of rate is far more than $75 \%$, far more than in the construction stage of cost control, therefore, in the engineering design phase of the project cost control of the use of the thought of beforehand control, and greatly improve the efficiency of engineering cost management .The participation of the design unit in the project cost management includes the following points: The use of BIM's design function, firstly, design the limit according to the drawings and specifications in the preliminary design stage of the project, and prepare the preliminary design budget .Secondly, in the technical design stage, some complicated engineering projects are modified by BIM to correct the previous designs and estimates. At the stage of construction drawing design, the design of construction drawing is designed and the design budget is verified, and the construction drawing budget is used as the basis for bidding, contract price and project settlement. Finally, the design changes are carried out according to various changes in the whole process of cost control [9].

\section{B. Supervision Organization Sub-platform}

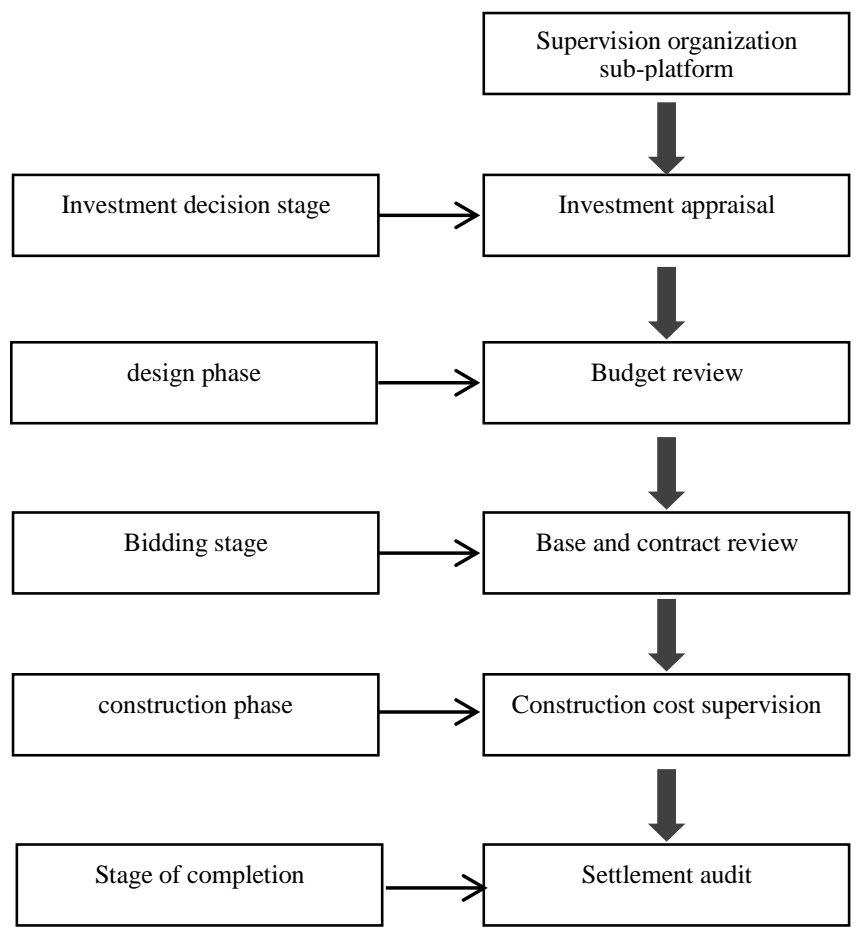

FIGURE III. SCHEMATIC DIAGRAM OF THE FUNCTION OF THE SUB-PLATFORM OF THE SUPERVISION ORGANIZATION

The supervising organization has a vital role in the process of construction of the project construction, which is responsible for supervising and controlling the operation of the project and ensuring the optimal realization of the project objectives. The specific project construction management contents of supervision organization include: analysis of the possibility of project construction, technical suitability, and rationality of economic benefits at the stage of project investment decision-making. Constructive opinions are submitted through the BIM construction platform and investment estimates of the project are reviewed. In the design stage, the supervision organization will assist the construction unit to select the better design scheme, review the design plan budget, propose optimal suggestions, and improve the efficiency of cost control [10]. During the 
tendering and bidding stage, the supervision unit shall calculate the contract price and make adjustments. During the construction phase, the supervision unit should manage the contract price, as an important basis for the control of cost, and can monitor the progress of the project through BIM; in the stage of competition, the supervising unit shall carefully check and examine the completed settlement book and the budget contract, and just handle the project claims event.

\section{Construction Organization Sub-platform}

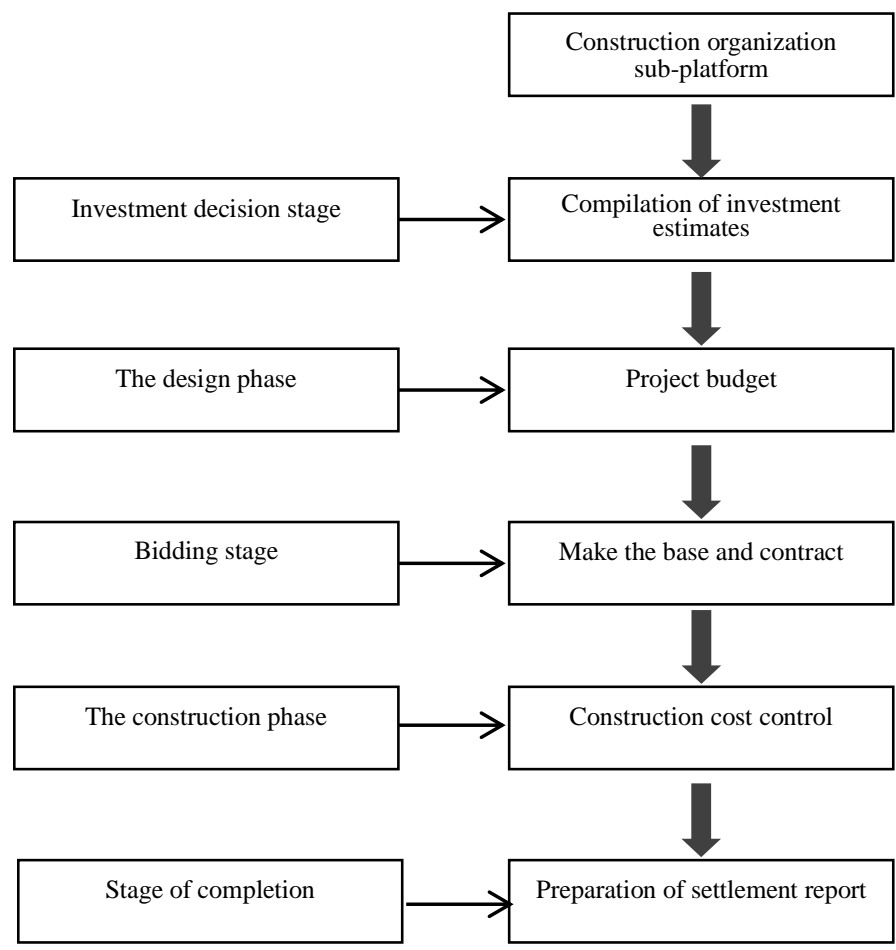

FIGURE IV. SCHEMATIC DIAGRAM OF THE FUNCTION OF BUILDING ORGANIZATION SUB-PLATFORM

The construction organization's management of the project cost is all periodicity, which is the whole process from the investment decision stage to the completion stage [11]. Construction organization plays a leading role in engineering cost management. Therefore, the construction organization sub-platform is one of the core parts of the project cost cloud platform. The main function of construction organization sub-platform are as follows: In the investment decision-making stage, the most important task of the construction unit in project cost management is to compile an investment estimation report to ensure the scientificity and applicability of the investment and lay a good foundation for the entire cost management. In the design stage, the construction unit based on the basic design of the design plan based on BIM preliminary project project cost estimate, and make it more rationalized. In the bidding stage, the bid price and contract management shall be determined, in which the contract management shall carefully contain all relevant contents, including the bill of quantities, the contracting mode and other materials and contents. The construction organization is the core of the construction stage, who is mainly responsible for the control of cost, such as design, contract price, change and adjustment of the project price, monitoring of project volume progress, and claim management. During the completion phase, the construction organization is mainly responsible for the preparation and review of the final accounts.

\section{Cost Consulting Sub-platform}

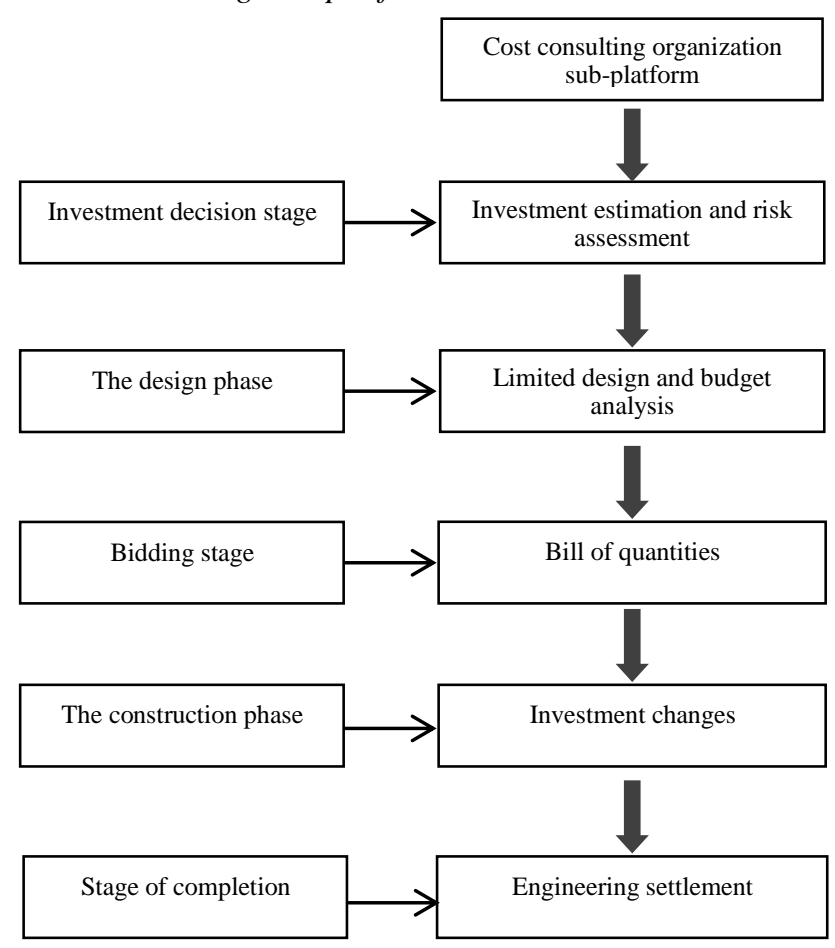

FIGURE V. SCHEMATIC DIAGRAM OF THE FUNCTION OF COST CONSULTING ORGANIZATION SUB-PLATFORM

Cost consulting organization is the core professional personnel of engineering cost management, which plays a decisive role in cost management. The main task is to provide the consulting service of cost related[12]. The main function of cost unit sub-platform are as follows: in the investment decision-making stage, the cost consultation unit can be obtained through BIM commissioned detailed information of the project, analysis and research for the construction organization to make a more accurate investment estimation, and according to the market change to evaluate investment risk and puts forward the solution. During the design stage, the design of the design organization selection is used the method of technical and economic optimal scheme to upgrade, in strict accordance with the quotas and shall not exceed the budget control scheme design, based on BIM in detail to calculate the cost of tender. In the bidding stage, cost consultation organization need to do list of quantities pricing, formulate scientific and rational use of funds allocation, provide the basis for tendering and bidding, contract signing, and put forward the corresponding reference opinions. During the construction phase, the cost consulting organization needs to put forward the cost control opinions according to the actual needs of the project, and make modification changes to realize better cost management[13]. During the completion 
phase, do a good job of project settlement, final accounts, and fair handling of claims.

\section{E. Cost Management Department's Sub-platform}

The project cost management department is the government participating in the control project cost department. The main task is to implement macro and micro regulation of the project cost to ensure the rationality of the project price. The main functions of the cost management department are as follows: analysis and compilation of various types of quotas through the BIM cloud cost platform analysis, which serves as the basis for cost management of projects in different periods; release of industry information, including market price information, cost indicators, and cost-related employees and units Qualifications, etc.[14]; Disposal of engineering disputes, that is to provide professional advice and arbitration for disputes encountered during the construction process.

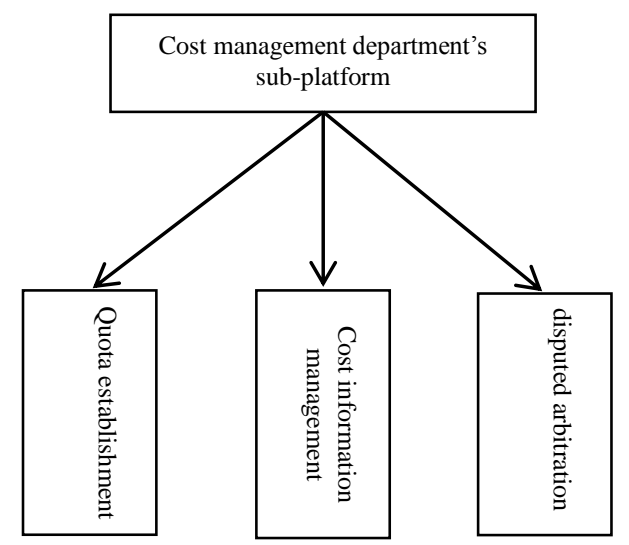

FIGURE VI. A SCHEMATIC DIAGRAM OF THE FUNCTION OF THE COST MANAGEMENT DEPARTMENT

\section{OVERALL ARCHITECTURE}

\section{A. Architectural Patterns}

This paper adopts a client/server architecture (Browser/Server) hybrid architecture model, which integrates the advantages of the two models into one, meets different usage requirements, and can save costs and increase Sharing, but also can improve part of the operating speed and improve efficiency.

\section{B. Overall Structure}

The BIM-based project cost cloud platform is different from the traditional cloud cost platform in the overall architecture. The traditional cost of cloud platform adopts "three layer architecture" mode: the data layer, logical application layer and presentation layer, while BIM provides a new model layer for the framework of platform, composed of four layers architecture model.

\section{1) Data layer}

The application of BIM provides a new idea for the data layer architecture of the project cost cloud platform. It expands the data content, enhances the accuracy of the data, and improves the operating efficiency of the data.

\section{a. Content of data}

Engineering cost management requires a large amount of data information, so the data content contains a wide range of information. Specific contents include:

Cost knowledge data. Cost data as the professional core knowledge of the data content, including the country, the department of industry, local laws, regulations, rules and regulations, and the country, the departments and local standards of construction, standard atlas, engineering scale, cost index, the price of staff, material, machine, etc.

Engineering data. Engineering data can be divided into the completed engineering data and the building of engineering data, including BIM platform in the $2 \mathrm{~d}$ and $3 \mathrm{~d}$ model data, bill of quantities, contract information, estimation, budget, budget, settlement statements, change of quantities and the related data of construction.

Public data. Public data is available for all people, including the industry development, the basic information of the relevant cost practitioners or institutions, the reputation of evaluation, knowledgeable skills and so on.

\section{b. Data acquisition}

With the BIM platform, all participants in the project work together to build a database of cloud-cost platforms that can quickly obtain more comprehensive and accurate data information. Each participant uses the platform to achieve data sharing.

\section{c. Data storage}

According to the IFC central database storage data, the application system is allowed to input, update, modify and export data through Internet connection on the basis of establishing a unified data storage standard.

\section{2) The layer of logic application}

The layer of logic application is the core layer of the whole platform, which activates the data in the platform and integrates operation to realize all the application functions [15]. For multi-party BIM project cost cloud platform, the logic application layer will provide different functions for different users. By using the logical application layer and obtaining the result information needed by the user, the platform can form a complete system.

\section{3) The layer of presentation}

The layer of presentation is also referred to as the interface layer or connected layer. Users can issue a command through the presentation layer, and the presentation layer displays the result [16] after the logical application layer executes the command. Typically, the browser and client pages in mixed architecture mode are the presentation layer for the platform. This article emphasizes the personalization of the presentation layer. In this article, the cloud-cost platform interface portal includes the supervision unit portal, design unit portal, cost unit portal, construction and construction unit portal, and cost management portal, which means that for different project participants, the platform the interface has different operation and display, so as to improve the operating efficiency of the platform function. 
4) The layer of model

BIM platform can accommodate all model contents of the project, including CAD drawings, $3 \mathrm{~d}$ model, program design, construction design drawings and so on. The editing, updating, and correction of model parameters and various forms of graphic transformation functions are usually served in a professional design, while the output function of the model can be mentioned to all related projects from the participants.

\section{CONCLUSION}

BIM technology provides a huge storage center for design information, engineering information, cost information and other relative information in the whole life cycle of construction projects. It solves the problem of inadequate information sources and difficult to reuse information in traditional cost management. Based on the research of using requirements of BIM cost project cloud platform, according to the design principles and objectives, the paper adopt abstract theory to arrange reasonably the function application and overall design of the cost cloud platform. It will lay a solid foundation for further promoting the development of information management and improving the efficiency of cost management.

\section{ACKNOWLEDGEMENTS}

The study was supported by "Science and Technology Project of Jiangxi education department, China (Grant No. GJJ160575)"

\section{REFERENCES}

[1] Dan Li. Exploration and innovation of engineering cost in the era of BIM [J]. China's western technology, 2015(8): pp.73-75.

[2] Qian Chen, Ying Zhang. The BIM standard study of bidding control price [J]. The Value engineering, 2014, 33(25): pp.91-92.

[3] Ying Wang, Yang Li, Tingkui Wang. Research on the framework of the information system for the life-cycle cost management of BIM [J]. Journal of engineering management, 2012, 26(3): pp22-27.

[4] Xiaofei Yin. Research on construction cost management based on BIM and IPD collaborative management model [D]. Dalian: dalian university of technology.2015.

[5] Shujie Zhang. Application of BIM in engineering cost management [J].Architecture economy, 2012(2):pp.20-24.

[6] Zuoming Wu, An Jinghe, Guo Jingjuan, etc. Review and prospect of China's engineering cost informationization [J]. Engineering cost management, 2014 (6):pp.7-13.

[7] Keke Du. Establishment and application of construction cost information and index system platform in chongqing [D]. Chongqing: chongqing university. 2007.

[8] Jie Li. Discussion on project cost management of participating parties in engineering construction [J]. Journal of tongling college, 2002, 4(1):pp.44-47.

[9] Yanhui Leng, shuwen Tao. Analysis and discussion on the effective control analysis of construction engineering design and engineering cost [J]. New Chinese new technology products, 2008(7):pp.137-137.

[10] Wen Wang. Research on project cost management of construction project implementation phase [D]. Beijing: China university of geosciences.2012.

[11] Ping Yuan. The whole process management and control of construction unit's construction cost of construction project [J]. Journal of zhongnan university of forestry science and technology (social science edition), 2015, 17(3):pp.47-48
[12] Zheng Li, Chunrong Zhou. Discussion on the whole process cost management of the construction project of the cost advisory unit [J]. Heilongjiang technical information, 2012 (33): pp.122-122.

[13] Ping Tao, Gang Luo. Research on process cost control of engineering consulting company $[\mathrm{J}]$. Journal of engineering management, 2010, 24(6): pp.704-708.

[14] Kewei Tang, jianguo Chen .Information analysis and online system development of engineering cost $[\mathrm{J}]$. Journal of engineering management, 2003(4): pp.17-21.

[15] Changjun Shu. Integration of construction cost information management system [D]. Wuhan: han university of technology.2013.

[16] Zaifang Tang, Qi Zong. User interface design of blasting engineering cost system [J]. Coal mine blasting, 2004(4):pp.27-28. 